\title{
Efficacy and safety of benzalkonium chloride-free fixed-dose combination of latanoprost and timolol in patients with open-angle glaucoma or ocular hypertension
}

\author{
This article was published in the following Dove Press journal: \\ Clinical Ophthalmology \\ 28 June 2014 \\ Number of times this article has been viewed
}

\author{
Purvi Bhagat' \\ Kalyani Sodimalla ${ }^{2}$ \\ Chandrima Paul ${ }^{3}$ \\ Surinder S Pandav ${ }^{4}$ \\ Ganesh V Raman ${ }^{5}$ \\ Rengappa Ramakrishnan ${ }^{6}$ \\ Abhijeet Joshi ${ }^{7}$ \\ Atul Raut ${ }^{7}$ \\ 'Glaucoma Clinic, M \& J Western \\ Regional Institute of Ophthalmology, \\ Civil Hospital, Ahmedabad, Gujarat, \\ India; 'laucoma Department, PBMA's \\ H.V. Desai Eye Hospital, Maharashtra, \\ India; ${ }^{3}$ Glaucoma Service, B B Eye \\ Foundation, Kolkata, India; ${ }^{4}$ Advanced \\ Eye Centre, Postgraduate Institute \\ of Medical Education and Research, \\ Chandigarh, India; ${ }^{5}$ Glaucoma Clinic, \\ Aravind Eye Hospital, Coimbatore, \\ Tamilnadu, India; ${ }^{6}$ Glaucoma Clinic, \\ Aravind Eye Hospital, Tirunelveli, \\ Tamilnadu, India; ${ }^{7}$ Clinical Research \\ Department, Sun Pharma Advanced \\ Research Company Ltd, Mumbai, \\ Maharashtra, India
}

Background: Benzalkonium chloride (BAK) is a common preservative in topical ocular preparations; however, prolonged use may lead to deleterious effects on the ocular surface, affecting quality of life and reducing adherence to treatment and overall outcomes. This study compared the intraocular pressure (IOP)-lowering efficacy and safety of a novel once-daily, BAK-free, fixed-dose combination of latanoprost plus timolol with latanoprost or timolol administered as monotherapy or concomitantly.

Methods: This was a 6-week, randomized, open-label, parallel-group, active-controlled study in patients aged $\geq 18$ years with open-angle glaucoma or ocular hypertension. A total of 227 patients were randomized to either a once-daily, BAK-free, fixed-dose combination of latanoprost $0.005 \% /$ timolol $0.5 \%$ ophthalmic solution or concomitant administration of oncedaily latanoprost $0.005 \%$ plus twice-daily timolol $0.5 \%$ or once-daily latanoprost $0.005 \%$ monotherapy, or twice-daily timolol $0.5 \%$ monotherapy. Efficacy end points were assessed at three time points on visits at weeks 1, 2, 4, and 6 versus baseline.

Results: The IOP-lowering efficacy of the fixed-dose combination of latanoprost/timolol was similar to that of latanoprost plus timolol administered concomitantly at all time points (mean IOP difference and $95 \%$ confidence interval within $\pm 1.5 \mathrm{mmHg} ; P=0.4223$ to $P=0.9981$ ). The fixed-dose combination of latanoprost/timolol demonstrated significantly better IOP-lowering efficacy than timolol monotherapy at all time points $(P=0.001$ to $P<0.0001)$ and significantly better IOP-lowering efficacy than latanoprost monotherapy at all time points. Responder rates on at least one time point and on at least two time points with fixed-dose combination latanoprost/ timolol were similar to those with concomitant latanoprost plus timolol $(85.5 \%$ versus $82.1 \%$, $P=0.6360 ; 78.2 \%$ versus $75 \%, P=0.6923)$, but significantly better than either latanoprost or timolol monotherapy $(68.5 \%, P=0.0355 ; 55.4 \%, P=0.0005 ; 57.4 \%, P=0.0202$; and $46.4 \%$, $P=0.0006$, respectively). No significant differences in ocular and nonocular treatment-emergent adverse events were found between the treatment groups.

Conclusion: A BAK-free, fixed-dose combination of latanoprost $0.005 \%$ /timolol $0.5 \%$ was as effective and well tolerated as concomitant latanoprost and timolol for treatment of elevated IOP in patients with open-angle glaucoma or ocular hypertension.

Keywords: open-angle glaucoma, ocular hypertension, pharmaceutical preservatives, benzalkonium chloride, latanoprost, timolol

\section{Introduction}

Control of elevated intraocular pressure (IOP) remains the principal goal in the treatment of glaucoma and ocular hypertension (OHT). ${ }^{1}$ The evidence suggests that achieving low IOP with treatment is associated with reduced progression of visual field
Clinical Research, Sun Pharma Advanced Research Company Ltd, I7-B Mahal Industrial Estate, Mahakali Caves Road, Andheri (E), Mumbai 400093 , Maharashtra, India

$\mathrm{Tel}+912266455752$

Fax +91 2266455685

Email atul.raut@sparcmail.com 
defect, and that this association becomes more prominent with increased duration of follow-up. ${ }^{1}$

Despite advances in laser and surgical treatments that improve trabecular drainage, pharmacologic therapy remains the primary intervention for most patients with glaucoma and OHT, and typically involves application of topical hypotensive agents. Because glaucoma is a chronic disease, long-term treatment with multiple ophthalmic medications is frequently required. Topically administered IOP-lowering medications include cholinergic agents, alpha 2 adrenergic agonists, carbonic anhydrase inhibitors, betaadrenoceptor antagonists (beta-blockers), and prostaglandin analogs. ${ }^{2}$

Patients are often initiated on monotherapy, such as a beta-blocker, which acts by decreasing production and secretion of aqueous humor. ${ }^{3}$ The evidence suggests that beta-blockers effectively lower IOP, have a long duration of action allowing once-daily or twice-daily administration, and are associated with few ocular side effects. ${ }^{4-6}$ Topical prostaglandin analogs are also increasingly selected as initial therapy in open-angle glaucoma (OAG). These lower IOP by increasing the uveoscleral outflow of aqueous humor, are very effective in reducing IOP, and require only once-daily administration. ${ }^{4,7,8}$

In up to $40 \%$ of patients, however, monotherapy does not provide sufficient lowering and control of IOP, and combination therapy is required. ${ }^{9}$ Studies have indicated that certain fixed-combination therapies can offer additive or synergistic activity, thereby inducing a more effective reduction in IOP than the individual monotherapies., ${ }^{3,10}$ Beta-blockers are commonly coprescribed along with prostaglandin analogs as part of a multidrug regimen. ${ }^{10}$ Latanoprost, a prostanoid selective prostaglandin $\mathrm{F}$ receptor agonist, and timolol, a nonselective beta-adrenergic receptor blocking agent, are indicated for the reduction of elevated IOP in patients with OAG or OHT. ${ }^{11,12}$ Studies have suggested that combining latanoprost and timolol in one product provides the convenience of once-daily dosing, with an IOP-lowering efficacy that is greater than that of either component product alone and is similar to the concomitant administration of the component products. ${ }^{10,13-18}$

Fixed-dose combinations also have the potential to promote better adherence, in addition to other potential benefits, including improved convenience, reduced exposure to preservatives, and cost reductions. ${ }^{19,20}$ Improved adherence has been demonstrated with fixed-dose combination regimens compared with unfixed concomitant therapies in a metaanalysis of pharmacologic treatments, and also in a study of patients switching from concomitant use of latanoprost and timolol eye drops to latanoprost/timolol combination eye drops. ${ }^{21,22}$ Adherence to treatment is particularly important in chronic conditions such as glaucoma. Patients typically lose peripheral vision and may completely lose vision unless consistent lifelong treatment is received. ${ }^{23}$

Latanoprost-timolol maleate $0.005 / 0.5 \%$ weight/volume (w/v) ophthalmic solution is available in Australia, Canada, the European Union, Mexico, Norway, Venezuela, and Japan as Xalacom ${ }^{\circledR}$ (Pfizer Limited, Sandwich, Kent, UK). ${ }^{24}$ It offers the advantage of once-daily dosing as a fixed-dose combination, but contains benzalkonium chloride (BAK) $0.02 \% \mathrm{w} / \mathrm{v}$, a quaternary ammonium compound that acts as a preservative and solubilizer to dissolve latanoprost. BAK is an antimicrobial preservative commonly used in topical ophthalmic preparations that acts by disrupting microbial cell membranes and promoting cell death., ${ }^{2} 25$ The use of BAK in ophthalmic solutions, however, has demonstrated a number of disadvantages in both in vitro and in vivo models, including dose-dependent and time-dependent toxicity to the corneal epithelium, the conjunctival epithelium, the stroma, and tear film constituents. ${ }^{25-41}$ BAK may reduce epithelial cell integrity, impair healing, induce cytokine secretion, cause elevated production of conjunctival inflammatory cells, and reduce goblet cell numbers. Further, BAK may impair tear function and reduce tear film integrity through its effects on the integrity of the meibomian layer and disruption of the lipid film continuous multilayer structure, thus decreasing tear film break-up time. ${ }^{40,41}$ At the cellular level, BAK induces growth arrest, disrupts tight junctions, reduces the concentration of antioxidants, and increases epithelial cell apoptosis and cytotoxicity. ${ }^{42}$ These toxic side effects are important in the management of glaucoma because of cumulative BAK exposure associated with long-term use. ${ }^{25}$ Patients may experience symptoms typical of ocular surface disease, such as dryness, burning or stinging, itching, irritation, tearing, photophobia, foreign body sensation, grittiness, redness, fatigue, varying visual acuity, blurred vision, and hyperemia. These symptoms can have a substantial impact on a patient's quality of life and potentially lead to reduced adherence with treatment regimens. In addition, chronic inflammation of the ocular surface is associated with reduced efficacy of surgical filtration, which is often the last treatment resort for patients with glaucoma. ${ }^{2}$

Alternative preservatives have been developed, eg, SofZia ${ }^{\circledR}$ (Alcon Laboratories, Inc., Fort Worth, TX, USA), which contain boric acid and zinc chloride, and are associated with less ocular surface damage than detergent preservatives such as BAK, and also do not impair the meibum layer 
surface properties. ${ }^{25,41}$ Studies have indicated that a change from a BAK-containing formulation to one that is devoid of BAK can result in distinct improvement of tear break-up time, corneal staining, and ocular surface disease index..$^{25}$ In preclinical studies comparing travoprost with SofZia to latanoprost with BAK, toxicity and inflammation were reduced and damage to human corneal cells was decreased in the BAK-free preparation. ${ }^{29,43}$

Currently, there is no available BAK-free, fixed-dose combination of latanoprost/timolol. Therefore, a fixed-dose combination of latanoprost $0.005 \%$ and timolol $0.5 \%$ for once-daily administration that is free from BAK or any other solubilizers has been developed by Sun Pharma Advanced Research Company Ltd, Mumbai, India. This new formulation contains the preservatives zinc chloride, boric acid, and tromethamine, and has the potential to avoid the possible disadvantages associated with BAK. Reducing ocular irritation is essential in patients receiving long-term therapy for effective lowering of IOP. ${ }^{2,19,20}$ In addition, cold-chain storage is not required with this formulation, and its gelfree reservoir technology allows once-daily use, which may further improve treatment adherence. ${ }^{36}$

A 6-week, randomized, open-label, parallel-group, active-controlled study compared the IOP-lowering efficacy and safety of a fixed-dose combination of latanoprost $0.005 \%$ and timolol 0.5\% ophthalmic solution (Sun Pharma Advanced Research Company Ltd) once daily with that of latanoprost $0.005 \%$ ophthalmic solution (Xalatan ${ }^{\circledR}$; Pfizer Inc., New York, NY, USA) once daily and timolol $0.5 \%$ ophthalmic solution (Timoptic ${ }^{\circledR}$; Merck \& Co Inc., Whitehouse Station, NJ, USA) twice daily, administered as monotherapy and concomitantly, in patients with OAG or OHT. Based on the results of this Phase III study, the fixed-dose combination of latanoprost $0.005 \%$ and timolol $0.5 \%$ ophthalmic solution was approved by the Drug Controller General of India.

\section{Materials and methods Study design}

This was a 6-week, randomized, open-label, parallel-group, active-controlled Phase III study conducted at 17 sites in India. Patients were randomized to one of four treatment groups in a ratio of 1:1:1:1 using computer-generated randomization schemes: fixed-dose combination of latanoprost $0.005 \% /$ timolol $0.5 \%$ ophthalmic solution, administered once daily (9 pm); latanoprost $0.005 \%$ ophthalmic solution (Xalatan) once daily ( $9 \mathrm{pm}$ ) plus timolol $0.5 \%$ ophthalmic solution (Timoptic) twice daily ( 9 am and 9 pm) given 5 minutes after latanoprost in the evening; latanoprost $0.005 \%$ ophthalmic solution once daily (9 pm); or timolol $0.5 \%$ ophthalmic solution twice daily ( 9 am and $9 \mathrm{pm}$ ). All treatments were administered topically to the affected eye(s).

\section{Patients}

Patients were eligible if they were aged $\geq 18$ years with OAG or OHT, and had IOP $\geq 24 \mathrm{mmHg}$ and $\leq 36 \mathrm{mmHg}$ in one or both eyes, best-corrected visual acuity $6 / 60$ or better, and visual field defects based on either the Humphrey Swedish interactive threshold algorithm (mean deviation better than $-20 \mathrm{~dB}$ ), Octopus (mean defect score better than $13 \mathrm{~dB}$ ), or Medmont (average defect score better than $-17 \mathrm{~dB}$ ), and no central point depressed to $0 \mathrm{~dB}$. Patients were excluded if they had had intraocular conventional surgery or laser surgery within the past 6 months, refractive surgery in the study eye, or ocular trauma within the previous 3 months. Patients with angle closure glaucoma or a history of acute angle closure treated with a peripheral iridotomy, progressive retinal or optic nerve disease apart from glaucoma, history of chronic or recurrent severe inflammatory eye disease, clinically significant ocular disease that might have interfered with the study, concurrent conjunctivitis, keratitis, or uveitis in either eye, ocular medication other than hypotensive agents within 30 days prior to the baseline visit, women of childbearing potential not practicing birth control, any other significant systemic disease, or hypersensitivity to study medications were also excluded. The study eye was defined as the most suitable eye (ie, the eye that satisfied all inclusion criteria and had none of the exclusion criteria, irrespective of which eye had the higher IOP at the eligibility visit).

All patients provided written informed consent prior to enrollment. The trial was approved by the Drug Controller General of India and all relevant local ethics committees, implemented in accordance with Good Clinical Practice described in E6 Guidelines of the International Conference of Harmonisation, and registered on Clinical Trials Registry-India (CTRI number CTRI/2011/091/000077 [Access date: May 19, 2014]). ${ }^{44}$

\section{Prohibited medications}

The following classes of medications were not permitted during the study or for certain periods prior to the study: beta antagonists, alpha and beta agonists, miotics, oral/topical carbonic anhydrase inhibitors, and ocular hypotensives. Concurrent use of monoamine oxidase inhibitors or tricyclic antidepressants was also prohibited. Appropriate washout was given by discontinuation of existing glaucoma treatment 
as follows: beta antagonists (28 days), prostaglandin analogs (28 days), adrenergic agonists (14 days), cholinergic agonists (5 days), and carbonic anhydrase inhibitors (5 days).

\section{Efficacy assessments}

This study consisted of a total of seven visits, including screening and eligibility visits. Assessments were conducted across five study visits at baseline, 1, 2, 4, and 6 weeks (ie, days $7 \pm 1,14 \pm 2,28 \pm 2,42 \pm 2$ ). The primary efficacy end point was change from baseline in mean IOP in the study eye, which was assessed at three time points ( 9 am, $11 \mathrm{am}$, and $5 \mathrm{pm}$; all \pm 30 minutes) at each study visit using Goldmann applanation tonometry. Readings were collected in triplicate at intervals of 1 minute, and the mean value was reported. These time points provided the relevant peak trough effects of the drugs studied: 9 am represented the peak effect of latanoprost and trough effect of timolol; 11 am represented the peak effect for timolol; and 5 pm represented the trough effect for latanoprost and timolol. Morning medication was administered 15 minutes after assessment of IOP (for patients receiving latanoprost plus timolol and those receiving timolol alone). The same evaluator performed the IOP assessments and slit-lamp examinations (using the same instrument) for each patient, whenever possible, for the duration of the study.

Responder rates were also analyzed and assessed as the percentage of patients with IOP $\leq 18 \mathrm{mmHg}$ on at least one time point and the percentage of patients with $\mathrm{IOP} \leq 18 \mathrm{mmHg}$ on at least two time points at each follow-up visit.

\section{Safety assessments}

Safety assessments consisted of evaluation of adverse events, vital signs (heart rate and sitting blood pressure), and 12-lead electrocardiogram (at screening and week 6). In addition, specific ocular safety criteria included assessment of conjunctival hyperemia, evaluation of ocular signs using slit-lamp biomicroscopy (cornea, lens, iris, anterior chamber), best-corrected visual acuity (loss of two lines or more from baseline in visual acuity was reported as an adverse event), dilated funduscopy (retina, macula, choroid, optic nerve, vitreous, cup-disc ratio), automated perimetry and gonioscopy (screening visit only), dilated ophthalmoscopy (retina, choroid, vitreous, optic nerve head), and assessment of central corneal thickness using ultrasound pachymetry (eligibility visit only). Clinically significant change from baseline in conjunctival hyperemia was defined as an increase of one or more units from the maximum hyperemia score recorded at any time point during the baseline visit. Adverse events were reported for clinically significant increases in hyperemia. All safety parameter analyses, where applicable, included both eyes (study eye and nonstudy eye).

\section{Statistical analysis}

Assuming a standard deviation of $3.5 \mathrm{mmHg}$ in IOP reduction from baseline, a sample size of 50 evaluable patients in each treatment group was determined to be sufficient to detect a difference of $2 \mathrm{mmHg}$ in IOP between any two groups using a two-sided, two-sample Student's $t$-test for a significance level of 0.05 and a power of $80 \%$. This sample size was also sufficient to detect a $2 \mathrm{mmHg}$ change in IOP from baseline.

Efficacy was assessed in the intent-to-treat population with the last observation carried forward, which included all randomized patients who had a baseline visit assessment, received at least one dose of study medication, and had at least one on-therapy efficacy assessment. The per-protocol population consisted of all randomized patients with at least one on-therapy efficacy assessment and no major protocol violations. The safety population included all patients who were randomized and received at least one dose of study medication.

Comparisons were made using the paired Student's $t$-test within treatment groups and the unpaired Student's $t$-test between treatment groups for continuous variables. The chi-square test was used for categorical variables and the Mann-Whitney $U$ test for ordinal variables. All tests were two-tailed, with a significance level of 0.05 . Repeatedmeasures analysis of variance was used for the primary end point (change in IOP from baseline). All statistical analyses were performed using $\mathrm{SAS}^{\circledR}$ software version 9.1.3 (SAS Institute Inc., Cary, NC, USA).

\section{Results}

\section{Patients}

A total of 300 patients were screened at 17 sites in India. Of these, 227 patients met the eligibility criteria and were randomized to one of the four treatment groups: a fixed-dose combination of latanoprost/timolol $(n=56)$, concomitant latanoprost plus timolol (58 patients), latanoprost alone $(n=55)$, and timolol alone $(n=58)$. Patient disposition is shown in Figure 1. Of these patients, 216 (95.2\%) completed the study. Of the remaining eleven (4.8\%) patients who discontinued from the study, the reasons were lost to follow-up (latanoprost/timolol, $n=2$; latanoprost, $n=1$ ), major protocol violation (latanoprost plus timolol, $\mathrm{n}=1$; latanoprost, $\mathrm{n}=1$ ), withdrawal of consent (latanoprost plus timolol, $n=1$; latanoprost, $\mathrm{n}=1$ ), adverse events (latanoprost, $\mathrm{n}=1$ [corneal disorder]; timolol, $\mathrm{n}=1$ [bradycardia]), patient noncompliance 


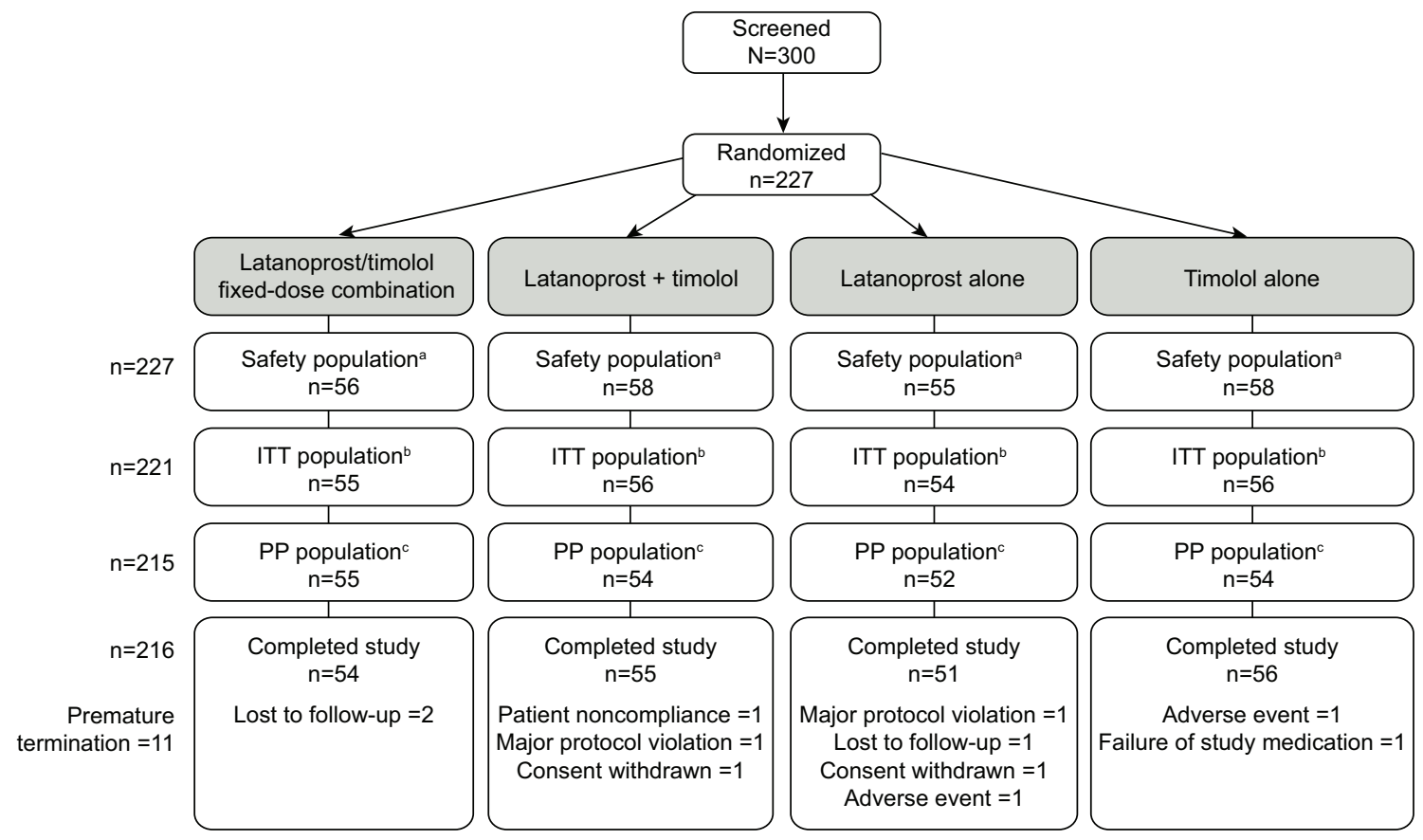

Figure I Patient disposition.

Notes: ${ }^{\text {TTh }} 227$ randomized patients represented the safety population, which included all patients who received at least one dose of study medication. bاTT population (efficacy analysis population) included all patients with baseline visit assessment who received at least one dose of study medication and at least one on-therapy efficacy assessment. Missing data were treated by last observation carried forward. 'PP population included patients with at least one on-therapy efficacy assessment and no major protocol violation.

Abbreviations: ITT, intent to treat; PP, per protocol; N/n, number.

(latanoprost plus timolol, $\mathrm{n}=1$ ), and failure of study medication (timolol, $\mathrm{n}=1$ ). All 227 patients randomized to receive treatment were considered as the safety population. The intent-to-treat population (efficacy analysis population) consisted of 221 patients, and the per-protocol population consisted of 215 patients.

Patient demographics, baseline characteristics, and baseline IOP of the intent-to-treat population are shown in Table 1. The overall mean population age was $55.0 \pm 13.53$ (range 20-83) years in this exclusively Asian patient population, and the majority of patients were male $(67.0 \%)$. Importantly, there was no statistically significant difference in baseline IOP values between the four treatment groups, which included a mean baseline IOP range of $25.79 \pm 2.84$ $\mathrm{mmHg}$ to $26.86 \pm 3.50 \mathrm{mmHg}$. In addition, there were no statistically significant differences in the number of patients with a history of OAG between the treatment groups. Slightly more patients in the latanoprost plus timolol group (33\% right eye, $32 \%$ left eye) had OHT compared with the fixed-dose combination group (25\% right eye, $27 \%$ left eye), latanoprost group ( $20 \%$ right eye, $19 \%$ left eye), and timolol group ( $22 \%$ for each eye). This variation in OHT between the groups was not regarded as being statistically significant.

\section{IOP assessments between}

\section{treatment groups}

Significant reductions in IOP from baseline were observed in all treatment groups at all time points over the 6-week treatment period (Figure 2). The IOP reduction with the fixed-dose combination of latanoprost/timolol was similar to that with concomitant latanoprost plus timolol. Mean IOP in the fixed-dose combination group and concomitant group was within $1.5 \mathrm{mmHg}$ at all 12 time points. In addition, the lower bound $95 \%$ confidence interval at 9 am and $11 \mathrm{am}$ at week 1 crossed the margin of $1.5 \mathrm{mmHg}$ in favor of the fixed-dose combination of latanoprost/timolol versus concomitant latanoprost plus timolol $(1.65 \mathrm{mmHg}$ and $1.53 \mathrm{mmHg}$, respectively).

The reduction in IOP from baseline with the fixed-dose combination of latanoprost and timolol was greater than with either latanoprost or timolol alone, regardless of time of day (Table 2). A statistically significant difference was demonstrated in favor of the fixed-dose combination of latanoprost/timolol versus latanoprost monotherapy at four time points: $11 \mathrm{am}$ and $5 \mathrm{pm}$ at week $2(P=0.0164$ and $P=0.0099$, respectively), 9 am at week $4(P=0.0148)$, and 11 am at week $6(P=0.0439)$. Further, a statistically significant difference in favor of the fixed-dose combination of latanoprost/timolol versus timolol 
Table I Patient demographic and baseline characteristics (ITT population)*

\begin{tabular}{|c|c|c|c|c|c|c|}
\hline \multirow[t]{2}{*}{ Category } & \multicolumn{6}{|c|}{ Treatment group } \\
\hline & \multicolumn{3}{|c|}{$\begin{array}{l}\text { Latanoprost/timolol fixed-dose } \\
\text { combination }(n=55)\end{array}$} & \multicolumn{3}{|c|}{ Latanoprost + timolol $(n=56)$} \\
\hline \multicolumn{7}{|l|}{ Sex, n (\%) } \\
\hline Male & \multicolumn{3}{|l|}{39 (70.9) } & \multicolumn{3}{|l|}{$38(67.9)$} \\
\hline Female & \multicolumn{3}{|l|}{$16(29.1)$} & \multicolumn{3}{|l|}{$18(32.1)$} \\
\hline \multicolumn{7}{|l|}{ Age (years) } \\
\hline Mean & \multicolumn{3}{|l|}{56.3} & \multicolumn{3}{|l|}{53.5} \\
\hline SD & \multicolumn{3}{|l|}{14.30} & \multicolumn{3}{|l|}{12.59} \\
\hline Range & \multicolumn{3}{|l|}{$24-83$} & \multicolumn{3}{|l|}{$22-72$} \\
\hline \multicolumn{7}{|c|}{ Iris color, n (\%) } \\
\hline Brown & \multicolumn{3}{|l|}{$55(100.0)$} & \multicolumn{3}{|l|}{$56(100.0)$} \\
\hline Hazel & \multicolumn{3}{|l|}{0} & \multicolumn{3}{|l|}{0} \\
\hline \multicolumn{7}{|c|}{ Mean baseline IOP $(\mathrm{mmHg})^{\mathrm{a}}$} \\
\hline & 9 am & II am & $5 \mathrm{pm}$ & 9 am & II am & $5 \mathrm{pm}$ \\
\hline Mean & 26.38 & 26.48 & 25.93 & 26.81 & 26.22 & 26.16 \\
\hline SD & 2.80 & 3.13 & 3.19 & 2.42 & 2.67 & 2.81 \\
\hline Range & $20.33-35.00$ & $20.00-37.66$ & $19.33-36.00$ & 19.67-33.33 & $19.33-32.33$ & $20.00-34.00$ \\
\hline$P$-value ${ }^{\mathrm{b}}$ & & & & 0.3942 & 0.6458 & 0.6870 \\
\hline Difference & & & & -0.42 & 0.25 & -0.23 \\
\hline $95 \% \mathrm{Cl}$ & & & & $-I .4 \mid$ to 0.56 & -0.84 to 1.35 & -1.36 to 0.90 \\
\hline
\end{tabular}

Notes: *Data shown are for the efficacy analysis (ITT) population. ${ }^{a}$ Mean IOP at baseline is for the study eye only. ${ }^{b} P$-value was calculated for each group compared with latanoprost/timolol fixed-dose combination at the corresponding time point, using unpaired Student's $t$-test.

Abbreviations: $\mathrm{Cl}$, confidence interval; IOP, intraocular pressure; ITT, intent to treat; SD, standard deviation.

monotherapy was indicated at all time points $(P=0.0010$ to $P<0.0001)$. These statistical data, which were confirmed by analysis of covariance, suggest an improved IOP-lowering efficacy for the fixed-dose combination of latanoprost/timolol versus latanoprost or timolol monotherapy.

\section{Responder rates}

When the responder rate was defined as the percentage of patients having IOP $\leq 18 \mathrm{mmHg}$ on at least two time points at each on-treatment follow-up visit, responder rates with the fixed-dose combination of latanoprost/timolol were numerically better than, but not significantly different to, those with concomitant latanoprost plus timolol $(78.2 \%$ versus $75 \%$, $P=0.6923$ ) and significantly better than those with latanoprost alone $(78.2 \%$ versus $57.4 \%, P=0.0202)$ or timolol alone (78.2\% versus $46.4 \%, P=0.0006$, Figure 3 ).

Similar results were observed when the responder rate was defined as the percentage of patients having IOP $\leq 18 \mathrm{mmHg}$ on at least one time point at each on-treatment follow-up visit. Responder rates with the fixed-dose combination of latanoprost/timolol were numerically better than, but not significantly different to, those with concomitant latanoprost plus timolol $(85.5 \%$ versus $82.1 \%, P=0.6360)$ and significantly better than those with latanoprost alone $(85.5 \%$ versus $68.5 \%, P=0.0355)$ and timolol alone $(85.5 \%$ versus $55.4 \%, P=0.0005)$.

\section{Safety}

\section{Ocular treatment-emergent adverse events}

During the study, 68 ocular treatment-emergent adverse events (TEAEs) were reported by 39 (17.2\%) patients, including 23 TEAEs by 12 (21.4\%) patients receiving fixed-dose combination latanoprost/timolol, 14 TEAEs by ten $(17.2 \%)$ patients receiving concomitant latanoprost plus timolol, 15 TEAEs by eight (14.5\%) patients receiving latanoprost alone, and 16 TEAEs by nine (15.5\%) patients receiving timolol alone (Table 3). No statistically significant differences in occurrence of ocular TEAEs were observed between the treatment groups. Eye irritation was the only ocular TEAE reported in $>5 \%$ of the overall safety population. Dry eye and eye pain were reported in the fixed-dose combination latanoprost/timolol group and conjunctival hyperemia was reported in the concomitant latanoprost plus timolol group in $>5 \%$ of patients. Ocular TEAEs were considered to be possibly related to treatment in $22(9.7 \%)$ patients and probably related to treatment in three $(1.3 \%)$ patients. Ocular TEAEs of moderate intensity occurred in six (2.6\%) patients and ocular TEAEs of mild intensity occurred in 33 (14.5\%) patients.

These data suggest that the fixed-dose combination of latanoprost/timolol was generally well tolerated, with no significant differences in ocular TEAEs, severe ocular TEAEs, or drug-related ocular TEAEs for patients receiving the 
Overall $(n=221)$

$36(66.7)$

$18(33.3)$

56.2

14.38

20-78

$53(98.1)$

I (I.9)

$\begin{array}{ll}9 \mathrm{am} & \mathrm{II} \mathrm{am} \\ 26.25 & 26.59 \\ 2.69 & 3.1 \mathrm{I} \\ 20.66-34.00 & 18.00-36.00 \\ 0.7983 & 0.8482 \\ 0.13 & -0.1 \mathrm{I} \\ -0.9 \mathrm{I} \text { to } \mathrm{I} .18 & -1.30 \text { to } \mathrm{I} .07\end{array}$

$35(62.5)$

$21(37.5)$

54.0

12.93

23-77

$56(100.0)$

0

$5 \mathrm{pm}$
25.79
2.84
$18.33-34.00$
0.8126
0.14
-1.01 to 1.28

$9 \mathrm{am}$
26.86
3.50
$19.66-39.00$
0.4318
-0.48
-1.67 to 0.72

$148(67.0)$

$73(33.0)$

55.0

13.53

20-83

$220(99.5)$

I (0.5) fixed-dose combination of latanoprost/timolol compared with patients in the other treatment groups. Importantly, no severe ocular TEAEs, drug-related serious ocular TEAEs, or deaths were reported during the study, and most ocular TEAEs were of mild intensity and resolved without medication.

\section{Nonocular treatment-emergent adverse events}

Nonocular TEAEs occurred in $<2 \%$ of patients (Table 4 ). Ten nonocular TEAEs were reported by eight $(3.5 \%)$ patients, comprising one (1.7\%) patient in the concomitant latanoprost plus timolol group (one TEAE), three (5.5\%) patients in the latanoprost alone group (four TEAEs), and four $(6.9 \%)$ patients in the timolol alone group (five TEAEs). No nonocular TEAEs were reported in patients receiving the fixed-dose of latanoprost/timolol. No statistically significant differences in the occurrence of nonocular TEAEs were observed between the treatment groups. One patient in the latanoprost group reported a nonocular TEAE that was considered to be of moderate intensity and the remainder of the patients had nonocular TEAEs of mild intensity. In addition, one nonocular TEAE (bradycardia in a patient receiving timolol) was considered to be probably related to treatment. No nonocular TEAEs were considered to be possibly related to treatment.

No statistically significant changes in conjunctival hyperemia grading, visual acuity, or dilated funduscopy parameters occurred with the fixed-dose combination of latanoprost/timolol. Further, no statistically significant difference was observed in these safety parameters across all four treatment groups.

During the study, $85(37.4 \%)$ patients received at least one concomitant medication, with $\geq 5 \%$ of the safety population receiving medication for diabetes (70 [30.8\%] patients), agents acting on the renin-angiotensin system (30 [13.2\%] patients), beta-blocking agents (19 [8.4\%] patients), calcium channel blockers (15 [6.6\%] patients), antithrombotic agents (14 [6.2\%] patients), and lipid-modifying agents (13 [5.7\%] patients).

\section{Discussion}

In this study, the IOP-lowering efficacy of the fixed-dose combination of latanoprost $0.005 \%$ /timolol $0.5 \%$ was similar to that of latanoprost plus timolol administered concomitantly. In addition, the fixed-dose combination of latanoprost $0.005 \%$ /timolol $0.5 \%$ demonstrated better IOPlowering efficacy and better responder rates than latanoprost or timolol administered alone. No significant differences in the occurrence of ocular and nonocular TEAEs were identified between the four treatment groups.

The efficacy of latanoprost and timolol use in fixedcombination therapy containing BAK versus either agent administered alone has previously been investigated in 


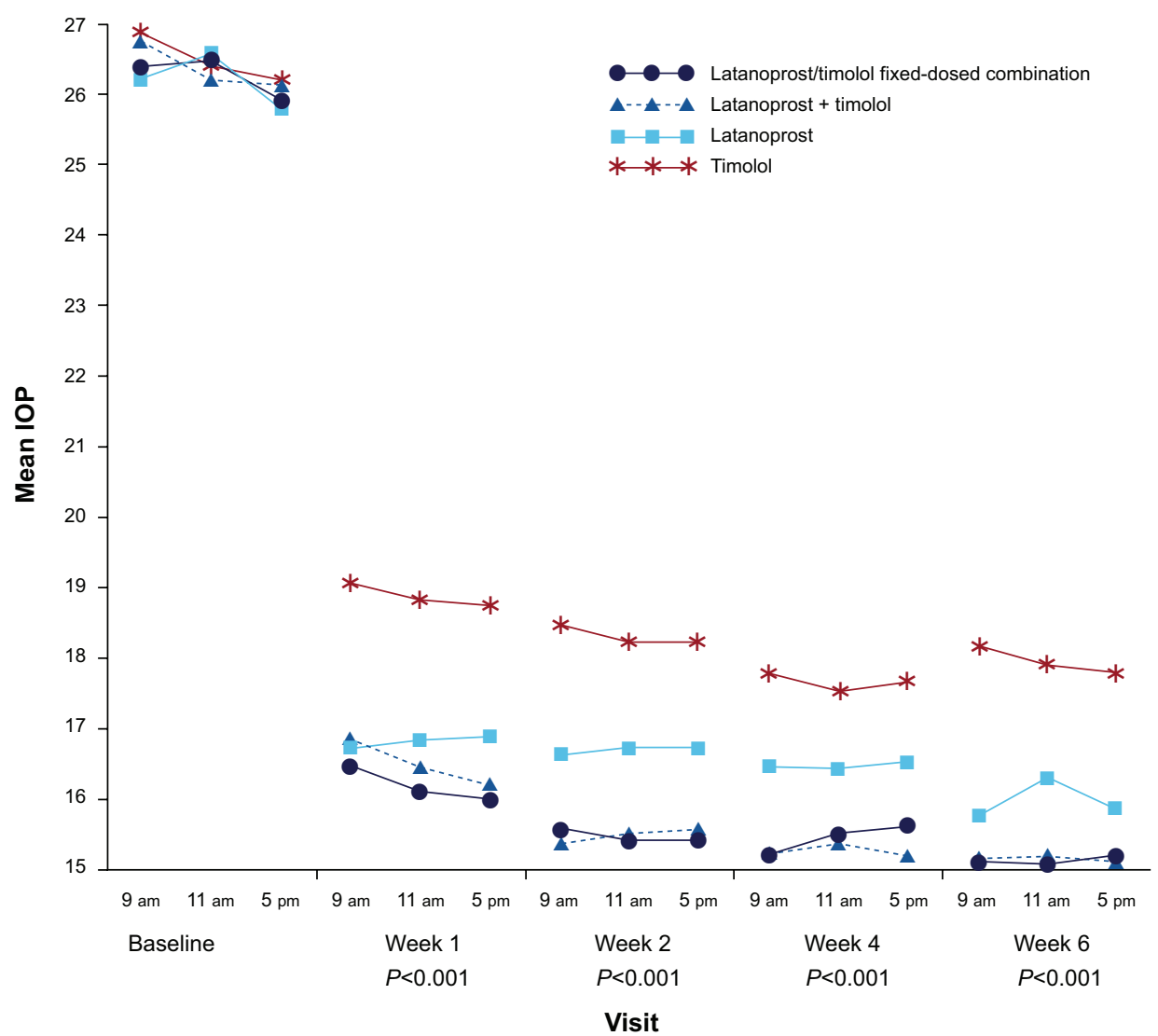

Figure 2 Mean IOP at each time point by visit.

Notes: Mean IOP is the mean per treatment group at each time point at each visit (day $7 \pm 1,14 \pm 2,28 \pm 2$, and $42 \pm 2$ ) during the 6-week treatment period. Data shown are from the efficacy analysis (ITT) population. P-value was calculated using a paired Student's $t$-test for comparing mean value from baseline (day 0 ) to mean value for week I (day 0 to day $7 \pm I$ ), week 2 (day 0 to day $14 \pm 2$ ), week 4 (day 0 to day 28 \pm 2 ), and week 6 (day 0 to day $42 \pm 2$ ) for each treatment group.

Abbreviations: IOP, intraocular pressure; ITT, intent to treat.

patients with glaucoma and OHT. Two 6-month randomized trials, each enrolling more than 400 patients, demonstrated that the mean IOP-lowering effect of the fixed-dose combined formulation was greater than that achieved by either agent given as monotherapy. ${ }^{14,18}$ Further, the IOP-lowering effect of fixed-dose latanoprost/timolol was maintained over a 6-month extension period. All treatments were well tolerated in both studies, with no significant differences observed for clinically relevant adverse events between treatment groups. ${ }^{14,18}$

Two more recent meta-analyses that assessed 18 and 20 randomized studies, respectively, provided further supporting data for the use of fixed-dose combinations of prostaglandin analogs and timolol as effective treatment options. The analyses found that combinations of prostaglandin analogs (latanoprost, bimatoprost, and travoprost) with timolol

Table 2 IOP change from baseline at each time point during 6 weeks of treatment with a fixed-dose combination of latanoprost/ timolol, concomitant latanoprost + timolol, latanoprost alone, and timolol alone

\begin{tabular}{|c|c|c|c|}
\hline \multirow[t]{2}{*}{ Treatment } & \multicolumn{3}{|c|}{ Mean change in IOP from baseline $(\mathrm{mmHg})$} \\
\hline & 9 am & II am & 5 pm \\
\hline Latanoprost/timolol fixed-dose combination & -9.91 to -11.29 & -10.34 to -11.38 & -9.92 to -10.73 \\
\hline Latanoprost + timolol & -9.94 to -11.64 & -9.74 to -11.01 & -9.92 to -11.04 \\
\hline Latanoprost & -9.52 to -10.48 & -9.76 to -10.27 & -8.90 to -9.92 \\
\hline Timolol & -7.82 to -9.08 & -7.61 to -8.89 & -7.47 to -8.57 \\
\hline
\end{tabular}

Notes: Mean IOP change shown is range from baseline at the time point indicated across treatment visits (day $7 \pm 1,14 \pm 2,28 \pm 2$, and $42 \pm 2$ ) during the 6 -week treatment period. Baseline IOP across the four treatment groups ranged from $25.79 \mathrm{mmHg}$ to $26.86 \mathrm{mmHg}$. Latanoprost/timolol fixed-dose combination was administered once daily at $9 \mathrm{pm}$, concomitant latanoprost + timolol was administered twice daily at 9 am (timolol only) and 9 pm (latanoprost + timolol), latanoprost monotherapy was administered once daily at 9 pm, and timolol monotherapy was administered twice daily at 9 am and 9 pm. Data shown are from the efficacy analysis (ITT) population. Last observation carried forward was applied for missing observations.

Abbreviations: IOP, intraocular pressure; ITT, intent to treat. 


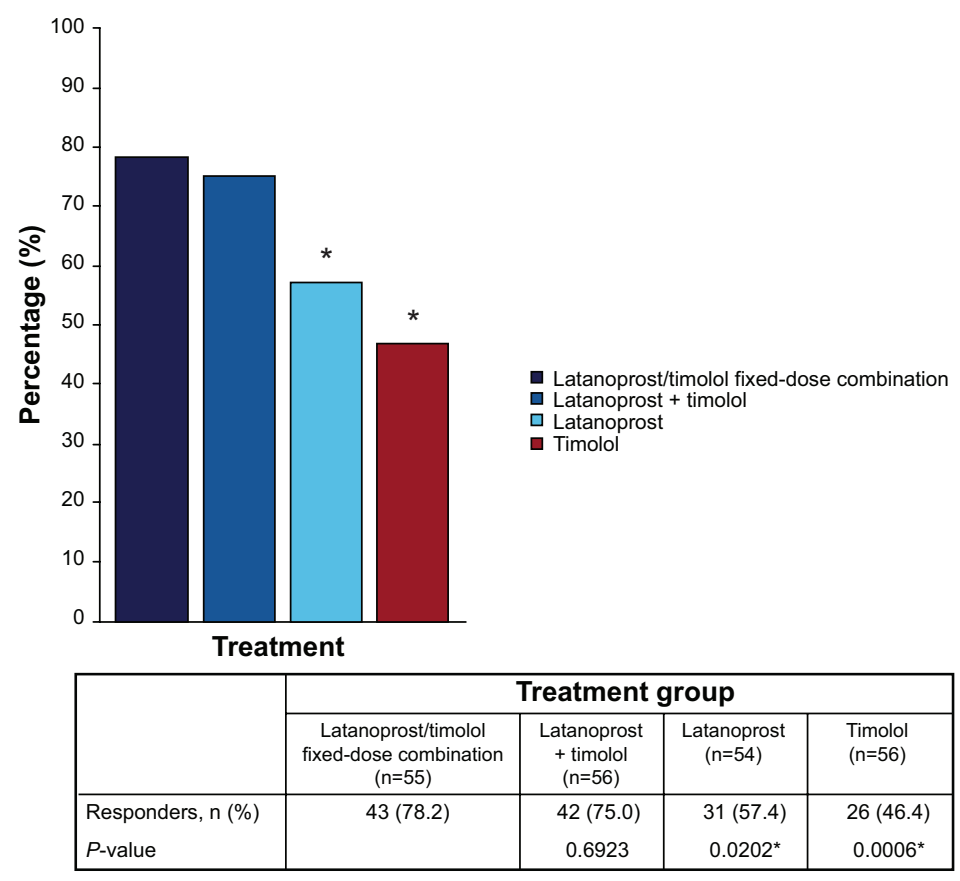

Figure 3 Responder rates (defined as patients having IOP $\leq 18 \mathrm{mmHg}$ for at least two time points at each follow-up visit) for the four treatment groups.

Notes: $P$-values were calculated using chi-square test for comparing treatment groups (each treatment group versus latanoprost/timolol fixed-dose combination group). Data shown are from the efficacy analysis (ITT) population. ${ }^{*}$ indicates a statistically significant $P$-value.

Abbreviations: IOP, intraocular pressure; ITT, intent to treat.

Table 3 Summary of ocular TEAEs reported during the course of the study (safety population)

\begin{tabular}{|c|c|c|c|c|c|}
\hline \multirow{2}{*}{$\begin{array}{l}\text { System Organ Class/ } \\
\text { Preferred Term }\end{array}$} & \multicolumn{5}{|l|}{ Treatment group } \\
\hline & $\begin{array}{l}\text { Latanoprost/timolol fixed- } \\
\text { dose combination }(n=56)\end{array}$ & $\begin{array}{l}\text { Latanoprost }+ \\
\text { timolol }(n=58)\end{array}$ & $\begin{array}{l}\text { Latanoprost } \\
(n=55)\end{array}$ & $\begin{array}{l}\text { Timolol } \\
(n=58)\end{array}$ & $\begin{array}{l}\text { Overall } \\
(n=227)\end{array}$ \\
\hline Total number of TEAEs, $n$ & 23 & 14 & 15 & 16 & 68 \\
\hline $\begin{array}{l}\text { Total number of patients with } \\
\text { at least one TEAE, } n(\%)^{*}\end{array}$ & $12(21.4)$ & $10(17.2)$ & $8(14.5)$ & $9(15.5)$ & $39(17.2)$ \\
\hline $\begin{array}{l}\text { Patients reporting TEAEs probably } \\
\text { related to treatment, } \mathrm{n}(\%)\end{array}$ & $\mathrm{I}(\mathrm{I} .8)$ & $2(3.4)$ & 0 & 0 & $3(1.3)$ \\
\hline $\begin{array}{l}\text { Patients reporting TEAEs possibly } \\
\text { related to treatment, } \mathrm{n}(\%)\end{array}$ & $8(14.3)$ & $5(8.6)$ & $3(5.5)$ & $6(10.3)$ & $22(9.7)$ \\
\hline $\begin{array}{l}\text { Patients reporting TEAEs unlikely } \\
\text { or not related to treatment, } \mathrm{n}(\%)\end{array}$ & $3(5.4)$ & $3(5.2)$ & $5(9.1)$ & $3(5.2)$ & $14(6.2)$ \\
\hline Eye disorders, n (\%) & $12(21.4)$ & $10(17.2)$ & $8(14.5)$ & $9(15.5)$ & $39(17.2)$ \\
\hline Conjunctival hyperemia & $\mathrm{I}(\mathrm{I} .8)$ & $3(5.2)$ & 0 & $\mathrm{I}(\mathrm{I} .7)$ & $5(2.2)$ \\
\hline Conjunctivitis & $2(3.6)$ & 0 & $2(3.6)$ & 0 & $4(1.8)$ \\
\hline Corneal disorder & 0 & 0 & $\mathrm{I}(\mathrm{I} .8)$ & 0 & I (0.4) \\
\hline Diabetic retinopathy & 0 & 0 & 0 & $\mathrm{I}(\mathrm{I} .7)$ & I (0.4) \\
\hline Dry eye & $3(5.4)$ & $\mathrm{I}(\mathrm{I} .7)$ & $\mathrm{I}(\mathrm{I} .8)$ & $2(3.4)$ & $7(3.1)$ \\
\hline Eye irritation & $4(7.1)$ & $6(10.3)$ & $2(3.6)$ & $5(8.6)$ & $17(7.5)$ \\
\hline Eye pain & $4(7.1)$ & $2(3.4)$ & $2(3.6)$ & $3(5.2)$ & II (4.8) \\
\hline Eye pruritus & $2(3.6)$ & $\mathrm{I}(\mathrm{I} .7)$ & $\mathrm{I}(\mathrm{I} .8)$ & 0 & $4(1.8)$ \\
\hline Foreign body sensation in eyes & $\mathrm{I}(\mathrm{I} .8)$ & $\mathrm{I}(\mathrm{I} .7)$ & $2(3.6)$ & 0 & $4(1.8)$ \\
\hline Lacrimation increased & $2(3.6)$ & 0 & $\mathrm{I}(\mathrm{I} .8)$ & $\mathrm{I}(\mathrm{I} .7)$ & $4(1.8)$ \\
\hline Macular edema & 0 & 0 & $\mathrm{I}(\mathrm{I} .8)$ & $\mathrm{I}(\mathrm{I} .7)$ & $2(0.9)$ \\
\hline Ocular hyperemia & $2(3.6)$ & 0 & 0 & 0 & $2(0.9)$ \\
\hline Photophobia & $2(3.6)$ & 0 & $\mathrm{I}(\mathrm{I} .8)$ & 0 & $3(1.3)$ \\
\hline Visual acuity reduced & 0 & 0 & $\mathrm{I}(\mathrm{I} .8)$ & 0 & $\mathrm{I}(0.4)$ \\
\hline
\end{tabular}

Notes: *All ocular TEAEs were mild or moderate in nature. Patients may have reported more than one event per System Organ Class or Preferred Term. Patients were counted once for each System Organ Class or Preferred Term at the maximum intensity/relationship experienced.

Abbreviation: TEAE, treatment-emergent adverse event. 
Table 4 Summary of nonocular TEAEs reported during the course of the study (safety population)

\begin{tabular}{|c|c|c|c|c|c|}
\hline \multirow{2}{*}{$\begin{array}{l}\text { System Organ Class/ } \\
\text { Preferred Term }\end{array}$} & \multicolumn{5}{|l|}{ Treatment group } \\
\hline & $\begin{array}{l}\text { Latanoprost/timolol fixed- } \\
\text { dose combination }(n=56)\end{array}$ & $\begin{array}{l}\text { Latanoprost }+ \\
\text { timolol }(n=58)\end{array}$ & $\begin{array}{l}\text { Latanoprost } \\
(n=55)\end{array}$ & $\begin{array}{l}\text { Timolol } \\
(n=58)\end{array}$ & $\begin{array}{l}\text { Overall } \\
(n=227)\end{array}$ \\
\hline Total number of TEAEs, $n$ & 0 & I & 4 & 5 & 10 \\
\hline $\begin{array}{l}\text { Total number of patients with at least } \\
\text { one TEAE, } n(\%)^{*}\end{array}$ & 0 & $\mathrm{I}(\mathrm{I} .7)$ & $3(5.5)$ & $4(6.9)$ & $8(3.5)$ \\
\hline $\begin{array}{l}\text { Patients reporting TEAEs probably } \\
\text { related to treatment, } \mathrm{n}(\%)\end{array}$ & 0 & 0 & 0 & $\mathrm{I}(\mathrm{I} .7)$ & $\mathrm{I}(0.4)$ \\
\hline $\begin{array}{l}\text { Patients reporting TEAEs possibly } \\
\text { related to treatment, } \mathrm{n}(\%)\end{array}$ & 0 & 0 & 0 & 0 & 0 \\
\hline $\begin{array}{l}\text { Patients reporting TEAEs unlikely } \\
\text { or not related to treatment, } n(\%)\end{array}$ & 0 & I (I.7) & $3(5.5)$ & $3(5.2)$ & $7(3.1)$ \\
\hline Cardiac disorders, n (\%) & 0 & 0 & 0 & $\mathrm{I}(\mathrm{I} .7)$ & $\mathrm{I}(0.4)$ \\
\hline Bradycardia & 0 & 0 & 0 & $\mathrm{I}(\mathrm{I} .7)$ & $\mathrm{I}(0.4)$ \\
\hline Gastrointestinal disorders & 0 & 0 & 0 & I (I.7) & I (0.4) \\
\hline Dyspepsia & 0 & 0 & 0 & $\mathrm{I}(1.7)$ & $\mathrm{I}(0.4)$ \\
\hline $\begin{array}{l}\text { General disorders and administration } \\
\text { site conditions }\end{array}$ & 0 & $\mathrm{I}(\mathrm{I} .7)$ & $\mathrm{I}(\mathrm{I} .8)$ & $\mathrm{I}(\mathrm{I} .7)$ & $3(1.3)$ \\
\hline Peripheral edema & 0 & $\mathrm{I}(\mathrm{I} .7)$ & 0 & 0 & $\mathrm{I}(0.4)$ \\
\hline Pyrexia & 0 & 0 & $\mathrm{I}(\mathrm{I} .8)$ & I (I.7) & $2(0.9)$ \\
\hline Infections and infestations & 0 & 0 & 0 & $2(3.4)$ & $2(0.9)$ \\
\hline Amebiasis & 0 & 0 & 0 & $\mathrm{I}(\mathrm{I} .7)$ & I (0.4) \\
\hline Nasopharyngitis & 0 & 0 & 0 & $\mathrm{I}(\mathrm{I} .7)$ & $\mathrm{I}(0.4)$ \\
\hline Metabolism and nutrition disorders & 0 & 0 & $\mathrm{I}(\mathrm{I} .8)$ & 0 & $\mathrm{I}(0.4)$ \\
\hline Vitamin $B_{12}$ deficiency & 0 & 0 & $\mathrm{I}(\mathrm{I} .8)$ & 0 & $\mathrm{I}(0.4)$ \\
\hline Nervous system disorders & 0 & 0 & $2(3.6)$ & 0 & $2(0.9)$ \\
\hline Headache & 0 & 0 & $\mathrm{I}(\mathrm{I} .8)$ & 0 & I (0.4) \\
\hline Muscle spasticity & 0 & 0 & $\mathrm{I}(\mathrm{I} .8)$ & 0 & $\mathrm{I}(0.4)$ \\
\hline
\end{tabular}

Notes: *All nonocular TEAEs were mild or moderate in nature. Patients may have reported more than one event per System Organ Class or Preferred Term. Patients were counted once for each System Organ Class or Preferred Term at the maximum intensity/relationship experienced.

Abbreviation: TEAE, treatment-emergent adverse event.

are more efficacious in reducing IOP than their individual components alone. ${ }^{10,45}$

In addition to the described potential efficacy advantages of use of fixed-dose combinations in OAG or OHT, such formulations may facilitate improved adherence and convenience for patients. Administration of therapies with simple regimens is critical in encouraging long-term use of an effective ocular hypotensive agent that might delay or prevent glaucomatous damage. ${ }^{46}$ The evidence suggests that poor adherence is an issue in patients treated with complex medication regimens for glaucoma. ${ }^{47-51}$ This finding is supported by studies in patients with other chronic conditions (human immunodeficiency virus, diabetes, hypertension) that suggest adherence to medical therapy is higher in patients receiving fixed-dose combination regimens versus those receiving unfixed concomitant therapies. ${ }^{21}$ Similar advantages of topical fixed combinations might be expected in the treatment of glaucoma. A recent study of 162 patients with glaucoma or OHT indicated that a switch from concomitant use of latanoprost $0.005 \%$ and timolol maleate $0.5 \%$ eye drops to latanoprost $0.005 \% /$ timolol maleate $0.5 \%$ combination eye drops improved adherence and helped to maintain IOP. ${ }^{22}$ Further evidence is required to understand fully the impact of fixed-combination therapies on the incidence of adverse events and long-term clinical outcomes. ${ }^{52}$

It has been demonstrated previously that a 6-week treatment period is sufficient to evaluate the safety and IOPlowering efficacy of a combination of a beta antagonist and prostaglandin analog. ${ }^{53}$ Nevertheless, longer-term studies comparing fixed-dose combinations of BAK-free and BAKpreserved formulations would help differentiate the potential long-term benefits of a BAK-free formulation. To address this clinical need, a Phase IV study is planned to collect realworld safety and efficacy data on this BAK-free latanoprost/ timolol fixed-dose combination.

Few studies have compared the long-term effects of BAK-free and BAK-preserved formulations for the treatment of patients with OAG or OHT. A study assessing treatment for 12 months in 114 patients receiving BAK-free travoprost after BAK-preserved latanoprost indicated fewer ocular surface complications (reduced prevalence of superficial punctate keratitis and decreased hyperemia), and no 
clinically relevant changes in IOP. ${ }^{54}$ Therefore, this BAK-free formulation of travoprost appeared to offer similar efficacy in IOP-lowering potential, with a lower incidence of adverse events than the BAK-preserved formulation. Further data are required to evaluate fully the possible advantages of BAKfree versus BAK-preserved formulations for the treatment of patients with glaucoma.

In summary, this 6-week study demonstrated that BAKfree, fixed-dose combination latanoprost $0.005 \% /$ timolol $0.5 \%$ was as well tolerated and as effective as latanoprost plus timolol administered concomitantly, and more effective than latanoprost or timolol administered alone, in the treatment of elevated IOP in patients with OAG or OHT. Therefore, this formulation offers patients the advantage of avoiding BAK while maintaining the convenience of once-daily administration, which may improve adherence. In addition, this formulation may be useful in patients with OAG or OHT who are currently using latanoprost and timolol combination therapy but who are intolerant to BAK, and in those for whom monotherapy alone does not provide sufficient IOP reduction.

\section{Acknowledgments}

Thanks are due to the following investigators who collected data and cared for patients participating in the study: Purvi R Bhagat, M \& J Western Regional Institute of Ophthalmology, Civil Hospital, Ahmedabad; Tejaswini Prasad Walimbe, Walimbe Eye Clinic, Pune; K Sodimalla, PBMA’s H.V. Desai Eye Hospital, Pune; Nilesh V Parekh, Department of Ophthalmology, Government Medical College and Sir Takhtsinhji Hospital, Bhavnagar; Pradeep L Jain, Netraseva, Jalna; Ganesh Venkata Raman, Aravind Eye Hospital and Postgraduate Institute of Ophthalmology, Coimbatore; Chandrima Paul, B B Eye Foundation, Kolkata; Sumit Choudhury, Eye Care and Research Centre, Kolkata; Surinder S Pandav, Advanced Eye Centre, Postgraduate Institute of Medical Education and Research, Chandigarh; Sushma Tejwani, Narayana Nethralaya Super Speciality Eye Hospital, Bangalore; Sonika Shah, Navkar Eye Clinic, Nashik; Yogesh Shah, Netra Mandir, Mumbai; R Ramakrishnan, Aravind Eye Hospital and Postgraduate Institute of Ophthalmology, Tirunelveli Junction; Sonal Shamik Ambatkar, Shaureen Advanced Eye Care, Nagpur; Ashish Thool, Netranjali Centre for Advanced Eye Care, Nagpur; Rekha Raju Khandelwal, NKP Salve Institute of Medical Sciences, Nagpur, India.

\section{Disclosure}

$\mathrm{PB}, \mathrm{KS}, \mathrm{CP}, \mathrm{SSP}, \mathrm{GVR}$, and RR have received research grants and nonfinancial support from Sun Pharma Advanced Research
Company Ltd, Mumbai, India. KS has a financial relationship with PBMA's H.V. Desai Eye Hospital, Maharashtra, India. AJ and AR are employees of Sun Pharma Advanced Research Company Ltd, which funded this study. The authors thank Mark Simmonds and Sue Harris of Quintiles for their editorial assistance with the manuscript, which was funded by Sun Pharma Advanced Research Company Ltd. The authors report no other conflicts of interest in this work.

\section{References}

1. The Advanced Glaucoma Intervention Study (AGIS): 7. The relationship between control of intraocular pressure and visual field deterioration. The AGIS Investigators. Am J Ophthalmol. 2000;130:429-440.

2. Kastelan S, Tomic M, Metez SK, Salopek-Rabatic J. How ocular surface disease impacts the glaucoma treatment outcome. Biomed Res Int. 2013;2013:696328.

3. Sambhara D, Aref AA. Glaucoma management: relative value and place in therapy of available drug treatments. Ther Adv Chronic Dis. 2014;5:30-43.

4. Dietlein TS, Hermann MM, Jordan JF. The medical and surgical treatment of glaucoma. Dtsch Arztebl Int. 2009;106:597-605.

5. Stewart RH, Kimbrough RL, Ward RL. Betaxolol vs timolol. A sixmonth double-blind comparison. Arch Ophthalmol. 1986;104:46-48.

6. Zimmerman TJ, Kaufman HE. Timolol. A beta-adrenergic blocking agent for the treatment of glaucoma. Arch Ophthalmol. 1977;95:601-604.

7. Toris CB, Gabelt BT, Kaufman PL. Update on the mechanism of action of topical prostaglandins for intraocular pressure reduction. Surv Ophthalmol. 2008;53 Suppl 1:S107-S120.

8. Uusitalo H, Pillunat LE, Ropo A. Efficacy and safety of tafluprost $0.0015 \%$ versus latanoprost $0.005 \%$ eye drops in open-angle glaucoma and ocular hypertension: 24-month results of a randomized, doublemasked phase III study. Acta Ophthalmol. 2010;88:12-19.

9. Kass MA, Heuer DK, Higginbotham EJ, et al. The Ocular Hypertension Treatment Study: a randomized trial determines that topical ocular hypotensive medication delays or prevents the onset of primary openangle glaucoma. Arch Ophthalmol. 2002;120:701-713.

10. Aptel F, Cucherat M, Denis P. Efficacy and tolerability of prostaglandintimolol fixed combinations: a meta-analysis of randomized clinical trials. Eur J Ophthalmol. 2012;22:5-18.

11. Xalatan ${ }^{\circledR}$. Package insert. New York, NY, USA: Pfizer Inc; 2011.

12. Timoptic ${ }^{\circledR}$. Package insert. Whitehouse Station, NJ, USA: Merck \& Co; 2005.

13. Costa VP, Moreira H, Paolera MD, de Moraes Silva MR. Efficacy and safety of travoprost $0.004 \%$ /timolol $0.5 \%$ fixed combination as transition therapy in patients previously on prostaglandin analog monotherapy. Clin Ophthalmol. 2012;6:699-706.

14. Higginbotham EJ, Feldman R, Stiles M, Dubiner H. Latanoprost and timolol combination therapy versus monotherapy: one-year randomized trial. Arch Ophthalmol. 2002;120:915-922.

15. Inoue K, Fujimoto T, Higa R, et al. Efficacy and safety of a switch to latanoprost $0.005 \%$ + timolol maleate $0.5 \%$ fixed combination eyedrops from latanoprost $0.005 \%$ monotherapy. Clin Ophthalmol. 2012;6:771-775.

16. Inoue K, Okayama R, Higa R, Wakakura M, Tomita G. Assessment of ocular hypotensive effect and safety 12 months after changing from an unfixed combination to a latanoprost $0.005 \%+$ timolol maleate $0.5 \%$ fixed combination. Clin Ophthalmol. 2012;6:607-612.

17. Palmberg P, Kim EE, Kwok KK, Tressler CS. A 12-week, randomized, double-masked study of fixed combination latanoprost/timolol versus latanoprost or timolol monotherapy. Eur J Ophthalmol. 2010;20: 708-718.

18. Pfeiffer N. A comparison of the fixed combination of latanoprost and timolol with its individual components. Graefes Arch Clin Exp Ophthalmol. 2002;240:893-899. 
19. Cheng JW, Cheng SW, Gao LD, Lu GC, Wei RL. Intraocular pressurelowering effects of commonly used fixed-combination drugs with timolol: a systematic review and meta-analysis. PLoS One. 2012; 7:e45079.

20. Higginbotham EJ. Considerations in glaucoma therapy: fixed combinations versus their component medications. Clin Ophthalmol. 2010;4:1-9.

21. Bangalore S, Kamalakkannan G, Parkar S, Messerli FH. Fixed-dose combinations improve medication compliance: a meta-analysis. Am J Med. 2007;120:713-719.

22. Inoue K, Okayama R, Higa R, Sawada H, Wakakura M, Tomita G. Ocular hypotensive effects and safety over 3 months of switching from an unfixed combination to latanoprost $0.005 \% /$ timolol maleate $0.5 \%$ fixed combination. J Ocul Pharmacol Ther. 2011;27: 581-587.

23. Kwon YH, Fingert JH, Kuehn MH, Alward WL. Primary open-angle glaucoma. N Engl J Med. 2009;360:1113-1124.

24. ADIS R\&D Insight. Available from: http://bi.adisinsight.com. Accessed January 20, 2014.

25. Horsley MB, Kahook MY. Effects of prostaglandin analog therapy on the ocular surface of glaucoma patients. Clin Ophthalmol. 2009;3:291-295.

26. Baudouin C, de Lunardo C. Short-term comparative study of topical $2 \%$ carteolol with and without benzalkonium chloride in healthy volunteers. Br J Ophthalmol. 1998;82:39-42.

27. Burstein NL. Preservative cytotoxic threshold for benzalkonium chloride and chlorhexidine digluconate in cat and rabbit corneas. Invest Ophthalmol Vis Sci. 1980;19:308-313.

28. Herreras JM, Pastor JC, Calonge M, Asensio VM. Ocular surface alteration after long-term treatment with an antiglaucomatous drug. Ophthalmology. 1992;99:1082-1088.

29. Kahook MY, Noecker RJ. Comparison of corneal and conjunctival changes after dosing of travoprost preserved with sofZia, latanoprost with $0.02 \%$ benzalkonium chloride, and preservative-free artificial tears. Cornea. 2008;27:339-343.

30. Kuppens EV, de Jong CA, Stolwijk TR, de Keizer RJ, Van Best JA. Effect of timolol with and without preservative on the basal tear turnover in glaucoma. Br J Ophthalmol. 1995;79:339-342.

31. Nakagawa S, Usui T, Yokoo S, et al. Toxicity evaluation of antiglaucoma drugs using stratified human cultivated corneal epithelial sheets. Invest Ophthalmol Vis Sci. 2012;53:5154-5160.

32. Noecker RJ, Herrygers LA, Anwaruddin R. Corneal and conjunctival changes caused by commonly used glaucoma medications. Cornea. 2004;23:490-496.

33. Norn MS, Opauszki A. Effects of ophthalmic vehicles on the stability of the precorneal film. Acta Ophthalmol (Copenh). 1977;55: 23-34.

34. Okahara A, Kawazu K. Local toxicity of benzalkonium chloride in ophthalmic solutions following repeated applications. J Toxicol Sci. 2013;38:531-537.

35. Pisella PJ, Pouliquen P, Baudouin C. Prevalence of ocular symptoms and signs with preserved and preservative free glaucoma medication. Br J Ophthalmol. 2002;86:418-423.

36. Wilson LA. To preserve or not to preserve, is that the question? $\mathrm{Br} J$ Ophthalmol. 1996;80:583-584.
37. Wilson WS, Duncan AJ, Jay JL. Effect of benzalkonium chloride on the stability of the precorneal tear film in rabbit and man. Br JOphthalmol. 1975;59:667-669.

38. Yalvac IS, Gedikoglu G, Karagoz Y, et al. Effects of antiglaucoma drugs on ocular surface. Acta Ophthalmol Scand. 1995;73:246-248.

39. Baudouin C. Detrimental effect of preservatives in eyedrops: implications for the treatment of glaucoma. Acta Ophthalmol. 2008;86: 716-726.

40. Georgiev GA, Yokoi N, Koev K, et al. Surface chemistry study of the interactions of benzalkonium chloride with films of meibum, corneal cells lipids, and whole tears. Invest Ophthalmol Vis Sci. 2011;52: 4645-4654

41. Georgiev GA, Yokoi N, Ivanova S, Krastev R, Lalchev Z. Surface chemistry study of the interactions of pharmaceutical ingredients with human meibum films. Invest Ophthalmol Vis Sci. 2012;53:4605-4615.

42. Kahook MY. Travoprost $Z$ opthalmic solution with sofZia: clinical safety and efficacy. Exp Rev Ophthal. 2007;2:363-368.

43. Yee RW, Norcom EG, Zhao XC. Comparison of the relative toxicity of travoprost $0.004 \%$ without benzalkonium chloride and latanoprost $0.005 \%$ in an immortalized human cornea epithelial cell culture system. Adv Ther. 2006;23:511-519.

44. Good Clinical Practice: E6 Guidelines of the International Conference of Harmonisation; Clinical Trials Registry, India. Available from: www. ctri.nic.in. CTRI identifier: CTRI/2011/091/000077. Accessed May 19, 2014.

45. Quaranta L, Biagioli E, Riva I, et al. Prostaglandin analogs and timololfixed versus unfixed combinations or monotherapy for open-angle glaucoma: a systematic review and meta-analysis. J Ocul Pharmacol Ther. 2013;29:382-389.

46. Schwenn O, Heckmann B, Guzy C, Miller PJ. Long-term effect of latanoprost/timolol fixed combination in patients with glaucoma or ocular hypertension: a prospective, observational, noninterventional study. BMC Ophthalmol. 2010;10:21.

47. Gurwitz JH, Glynn RJ, Monane M, et al. Treatment for glaucoma: adherence by the elderly. Am J Public Health. 1993;83:711-716.

48. Kass MA, Gordon M, Morley RE Jr, Meltzer DW, Goldberg JJ. Compliance with topical timolol treatment. Am J Ophthalmol. 1987;103: 188-193.

49. Patel SC, Spaeth GL. Compliance in patients prescribed eyedrops for glaucoma. Ophthalmic Surg. 1995;26:233-236.

50. Robin AL, Novack GD, Covert DW, Crockett RS, Marcic TS. Adherence in glaucoma: objective measurements of once-daily and adjunctive medication use. Am J Ophthalmol. 2007;144:533-540.

51. Tsai JC, McClure CA, Ramos SE, Schlundt DG, Pichert JW. Compliance barriers in glaucoma: a systematic classification. J Glaucoma. 2003;12:393-398

52. Konstas AG, Haidich AB, Rossetti L, Webers C. Prostaglandin-timolol fixed combinations efficacy: myth or reality? Eur J Ophthalmol. 2012;22:1-4

53. DuoTrav. Summary of Product Characteristics. Surrey, UK: Alcon Laboratories (UK) Ltd. 2013.

54. Aihara M, Otani S, Kozaki J, et al. Long-term effect of BAK-free travoprost on ocular surface and intraocular pressure in glaucoma patients after transition from latanoprost. J Glaucoma. 2012;21:60-64.
Clinical Ophthalmology

\section{Publish your work in this journal}

Clinical Ophthalmology is an international, peer-reviewed journal covering all subspecialties within ophthalmology. Key topics include: Optometry; Visual science; Pharmacology and drug therapy in eye diseases; Basic Sciences; Primary and Secondary eye care; Patient Safety and Quality of Care Improvements. This journal is indexed on Submit your manuscript here: http://www.dovepress.com/clinical-ophthalmology-journal
Dovepress

PubMed Central and CAS, and is the official journal of The Society of Clinical Ophthalmology (SCO). The manuscript management system is completely online and includes a very quick and fair peer-review system, which is all easy to use. Visit http://www.dovepress.com/ testimonials.php to read real quotes from published authors. 